\title{
Assessment of thrombocytopenic patients for splenectomy
}

\author{
J. D. M. RICHARDS AND D. S. THOMPSON \\ From the Department of Haematology, University College Hospital, Gower Street, London WC1, UK
}

SUMMARY Platelet survival and splenic sequestration patterns were studied in 32 patients with thrombocytopenia using donor platelets labelled with chromium-51. A shorter mean platelet lifespan was observed in immune thrombocytopenia (ITP) (mean 12 hours) than in hypersplenism (mean 56 hours) or marrow hypoplasia (mean 102 hours). There was no such correlation between diagnosis and splenic sequestration. A biphasic survival curve was seen in nine of 22 patients with ITP. Thirteen patients underwent splenectomy with complete (9) or partial (4) response, but no consistent pattern of results was manifest. It is concluded that in vivo isotope studies are of little value in predicting the benefit of splenectomy in thrombocytopenic patients, although they may demonstrate the mechanism of the thrombocytopenia, in particular the biphasic survival curve revealing separate 'immune' and 'hypersplenic' components of platelet destruction in ITP.

Thrombocytopenia may be due to decreased platelet production or to an increased rate of destruction. Increased destruction may be due to hypersplenism, immunological mechanisms, or a combination of both. Determination of the pattern of platelet survival and of the degree of splenic platelet sequestration may help to elucidate the underlying mechanism of destruciion and have been proposed as useful investigations for the prediction of the outcome of splenectomy in thrombocytopenic patients.

\section{Review of the literature}

The earliest determinations of platelet lifespan were carried out by transfusion of platelet-rich whole blood into thrombocytopenic recipients (Hirsch and Gardner, 1952). Schwartz (1974) measured the recovery of platelet aggregation after the ingestion of acetylsalicylic acid, normal aggregation being restored in two or three days in patients with immune thrombocytopenic purpura (ITP), other autoimmune diseases, and splenomegaly due to thalassaemia or sickle trait, whereas in control subjects the time was four to seven days. The majority of subsequent techniques have involved the use of radioactive labels, including ${ }^{32} \mathrm{P}$-di-isopropyl phosphate (Adelson et al., 1957; Leeksma and Cohen, 1956), ${ }^{14} \mathrm{C}$ serotonin (Heyssel, 1961), ${ }^{75} \mathrm{Se}-$-selenomethionine

Received for publication 9 May 1979
(Cohen et al., 1965), and ${ }^{51} \mathrm{Cr}$-sodium chromate (Aas and Gardner, 1958). Murphy and Gardner (1971) demonstrated that the results of platelet lifespan measurements are dependent on several procedural factors other than the technique used for labelling, namely, the type of anticoagulant, the nature of the wettable surface of the containers, and the immunological compatibility of the platelets.

Labelling with ${ }^{51} \mathrm{Cr}$ has teen found to be a satisfactory method for the following reasons: the isotope becomes firmly bound to the platelets within 20 minutes; the slow rate of isotope elution allows this factor to be disregarded in calculations; the energy spectrum of the gamma emissions is suitable for in vivo as well as in vitro counting within an acceptable dose to the patient (less than $50 \mu \mathrm{Ci}$ ). The platelet lifespan in normal subjects has been estimated to be nine to 11 days (216-264 hours) (Harker and Finch, 1969). The value of isotope studies in thrombocytopenia has been controversial. A close correlation between splenic sequestration and the benefit of splenectomy was demonstrated by Najean et al. (1967). The site of sequestration in ITP was further studied by these workers (Najean and Ardaillou, 1971), who concluded that where splenic sequestration can be clearly demonstrated, splenectomy gives both short- and long-term remission. They also suggested that the site of sequestration was not related to either the severity or the duration of the disease. However, these findings were in contradiction to those of Aster and Keene (1969), who sug- 
gested that sequestration could be related to the severity of the disease at the time of study and was of no value in deciding the benefit of splenectomy. Barkhan (1974) stated that, in chronic ITP, 'spleen scanning after infusing ${ }^{51} \mathrm{Cr}$-labelled platelets is not useful for selecting patients for splenectomy'. The exchangeable splenic pool of platelets has been studied in healthy subjects and in patients with splenomegaly of varying aetiology by Branehög $e t$ al. (1973). It was larger in patients with splenomegaly than in controls or patients suffering from ITP. However, the recovery of labelled platelets in these patients with ITP was less than in normal subjects, and therefore the exchangeable splenic platelet pool in ITP could not be determined by this method.

\section{Patients and methods}

Platelet survival studies were carried out on 32 patients with marked thombocytopenia (platelet counts $\left.10-50 \times 10^{9} / 1\right)$. Seventeen were male, 15 female, and their ages ranged from 5 to 70 years. Of these, 22 were diagnosed as suffering from ITP, 16 of acute onset one week to six months before the date of investigation, and six with a chronic history extending from 18 months to five years before investigation. Nine of the acute and three of the chronic cases had been treated with prednisone before investigation without significant improvement of the platelet count. Five patients had splenomegaly secondary to other diseases (Gaucher's disease, myelofibrosis, and portal hypertension) with documented thrombocytopenia for two months to nine years, and five had impaired platelet production with thrombocytopenia for one month to 13 years before investigation. All patients in these two groups were untreated at the time of investigation except one with phenylbutazone-induced marrow hypoplasia, who had received prednisone, oxymetholone, and platelet transfusions and is discussed further below.

Heterologous pooled platelet concentrates from five normal $\mathrm{ABO}$ and $\mathrm{Rh}$ compatible donors were used for each study. All donors were tested and found to be negative for $\mathrm{HBs} A g$, and no patient developed hepatitis during the period of follow-up. Blood was taken into ACD in standard transfusion packs, and the platelets were separated and labelled, as described by Dacie and Lewis (1975) using about $200 \mu \mathrm{Ci}{ }^{51} \mathrm{Cr}$ sodium chromate, and infused within 20-24 hours.

In vivo surface counting was performed using an Ekco N 717A collimated head fitted with a 2-inch sodium iodide crystal attached to a Harwell 2000 series counter. Precordial ('heart') counts were recorded over the left sternal border at the third costal interspace with the patient supine. Splenic countswere recorded at the area of highest registrable activity. For the majority of patients, particularly those without a clinically enlarged spleen, it was usual to count posteriorly with the patient in the right lateral position; however, when the spleen was palpable, higher counts were often obtained by counting anterolaterally with the patient supine. Counting was carried out for 5 minutes at each site.

Specimens for in vitro counting and estimation of platelet survival were taken into potassium EDTA at $30,45,60,90,120$, and 240 minutes after injection of the labelled platelets and thereafter daily while significant radioactivity persisted. Platelet-rich plasma (PRP) was separated by centrifugation at $250 \mathrm{~g}$ for 30 minutes. Duplicate aliquots of $2 \mathrm{ml}$ were transferred to graduated plastic centrifuge tubes and spun down, and the plasma was removed. Contaminating red cells were lysed with ammonium oxalate, and the platelets were washed in saline and resuspended in Isoton. Specimens were counted for 10 minutes in a Packard Autogamma Spectrometer, corrected for background, and expressed as counts per aliquot of PRP per 10 minutes. This is proportional to whole blood platelet aciivity in the original specimen, provided the preparation of the PRP is carefully standardised, and represents the proportion of the original injected dose still circulating. Good agreement was found between duplicates, and this method was preferred to the more usual expression of activity as a function of the platelet count in the PRP. The latter represents the proportion of circulating platelets still carrying the label, and calculation of survival on this basis will be subject to errors due to independent variation in numbers of unlabelled platelets during the time of the study. Total counts recorded were in the range 5000-20 000 but occasionally fell to $1-2000$ in late specimens (variance $5-10 \%$ ).

Results were expressed as a percentage of the peak post-injection activity and plotted against time on semilogarithmic paper. Mean platelet lifespan (MPL) was derived from the graph according to the formula:

$$
\text { MPL }=\frac{\mathrm{T}_{\frac{1}{2}}{ }^{51} \mathrm{Cr}}{\log _{\mathrm{e}} 2}=\frac{\mathrm{T}_{\frac{1}{2}}{ }^{51} \mathrm{Cr}}{0.69}
$$

assuming an exponential loss of platelets from the circulation (Ries and Price, 1974). In those with biphasic curves, the initial slope was extrapolated where necessary to obtain the $T \frac{1}{2}$ of the short-lived population.

\section{Results}

Details of patients and individual results are given 
in Tables 1 and 2. There was no correlation between the length of history of the ITP patients, or previous treatment, and any of the parameters measured or the need for subsequent splenectomy or its outcome.

Two patterns of platelet survival were identified: a single exponential curve (Fig. 1) was seen in patients with reduced production and those with secondary hypersplenism and in eight of 22 patients with ITP. On the other hand, nine of the latter group showed evidence of a double population with a biphasic survival curve (Fig. 2). In five patients with ITP the curves obtained did not fall clearly into either pattern. Splenic sequestration, as assessed by the spleen/heart ratio, varied widely and showed no significant correlation with diagnosis (Fig. 3), mean platelet lifespan, or shape of survival curve.

Mean platelet lifespan was 20 minutes to 75 hours (mean 12 hours) in ITP, and 30-87 hours (mean 56 hours) in secondary hypersplenism, compared with 77-129 hours (mean 102 hours) in marrow hypoplasia (Fig. 3). The mean lifespan tended to be shorter in

Table 1 Immune thrombocytopenia

\begin{tabular}{|c|c|c|c|c|c|c|c|c|}
\hline Case & $\begin{array}{l}\text { Age } \\
(y r)\end{array}$ & $\operatorname{Sex}$ & $\begin{array}{l}\text { Initial } \\
\text { platelet } \\
\text { count } \\
\left(\times 10^{\circ} / l\right)\end{array}$ & $\begin{array}{l}M P L \\
(h)\end{array}$ & $S / H$ & Splenectomy & $\begin{array}{l}\text { Length of } \\
\text { follow-up } \\
\text { (months) }\end{array}$ & $\begin{array}{l}\text { Recent } \\
\text { platelet } \\
\text { count } \\
\left(\times 10^{\circ} / l\right)\end{array}$ \\
\hline \multicolumn{9}{|c|}{ Biphasic survival curve } \\
\hline FN & 29 & $\mathbf{M}$ & $<10$ & $1 \cdot 0$ & $1 \cdot 3$ & YES & 26 & 220 \\
\hline GH & 22 & $\mathbf{F}$ & 40 & $3 \cdot 2$ & 3.6 & YES & 8 & 305 \\
\hline MI & 35 & $\mathbf{M}$ & 20 & $2 \cdot 0$ & 69 & YES & 24 & 420 \\
\hline JE & 23 & $\mathbf{F}$ & 20 & $1 \cdot 2$ & 15 & YES & 30 & 86 \\
\hline EM & 30 & $\mathbf{M}$ & 4 & $4 \cdot 4$ & 17 & NO & 12 & 150 \\
\hline DG & 26 & $\mathbf{M}$ & 34 & 17 & $3 \cdot 2$ & NO & 34 & $114^{*}$ \\
\hline SD & 20 & $\overline{\mathbf{M}}$ & $<10$ & $2 \cdot 2$ & 15 & YES & 16 & 630 \\
\hline EC & 64 & $\mathbf{F}$ & 43 & 12 & 21 & NO & 10 & 130 \\
\hline $\mathbf{M V}$ & 24 & $\mathbf{F}$ & $<10$ & $8 \cdot 4$ & 12 & NO & 10 & 126 \\
\hline \multicolumn{9}{|c|}{ Monophasic survival curve } \\
\hline RC & 35 & $\mathbf{M}$ & 15 & $7 \cdot 0$ & 16 & YES & 30 & 350 \\
\hline FF & 27 & $\mathbf{F}$ & 20 & 1.6 & 16 & YES & 3 & 255 \\
\hline HK & 14 & $\mathbf{F}$ & 34 & $7 \cdot 3$ & 15 & YES & 2 & 560 \\
\hline $\mathbf{S M}$ & 24 & $\mathbf{F}$ & $<10$ & $2 \cdot 0$ & 14 & YES & 2 & 35 \\
\hline $\mathbf{G B}$ & 58 & $\mathbf{M}$ & 10 & 75 & 12 & YES & $1 \overline{7}$ & 275 \\
\hline HL & 67 & $\mathbf{M}$ & 37 & 48 & 28 & NO & 15 & 112 \\
\hline $\mathbf{L S}$ & 35 & $\mathbf{F}$ & 30 & 28 & 8 & NO & 32 & $44^{*}$ \\
\hline $\mathbf{K M}$ & 8 & $\mathbf{M}$ & 30 & 10 & 3 & NO & 30 & $63 t$ \\
\hline \multicolumn{9}{|c|}{ Unclassified survival curve } \\
\hline HS & 31 & $\mathbf{F}$ & 3 & 25 & $5 \cdot 5$ & YES & 18 & 230 \\
\hline $\mathbf{A M}$ & 35 & $\mathbf{F}$ & $<10$ & 0.3 & 6 & YES & 34 & 70 \\
\hline SEH & 24 & $\mathbf{F}$ & 12 & $7 \cdot 3$ & 14 & YES & 6 & 108 \\
\hline MW & 54 & $\mathbf{F}$ & 34 & $\mathbf{n} / \mathbf{a}$ & 3 & NO & 54 & 146 \\
\hline $\mathbf{M P}$ & 5 & $\mathbf{F}$ & 6 & 10 & 130 & NO & 54 & $240 \ddagger$ \\
\hline
\end{tabular}

* Systemic lupus erythematosus

†Infectious mononucleosis

$\ddagger$ Unidentified virus infection

$\mathbf{M P L}=$ mean platelet lifespan $; \mathbf{S} / \mathbf{H}=$ spleen $/$ heart ratio; $\mathbf{n} / \mathbf{a}=$ not available

Table 2 Non-immune thrombocytopenia

\begin{tabular}{|c|c|c|c|c|c|c|}
\hline Case & $\begin{array}{c}\text { Age } \\
(y r)\end{array}$ & Sex & $\begin{array}{l}\text { Initial } \\
\text { platelet } \\
\text { count }\left(\times 10^{\circ} / L\right)\end{array}$ & $\begin{array}{l}\text { MPL } \\
\text { (h) }\end{array}$ & $\boldsymbol{S} / \boldsymbol{H}$ & Underlying diagnosis \\
\hline \multicolumn{7}{|c|}{ Thrombocytopenia secondary to hypersplenism } \\
\hline $\mathbf{R V}$ & 22 & $\mathbf{M}$ & 40 & 74 & 40 & Portal hypertension \\
\hline BS & 34 & $\mathbf{M}$ & 30 & 87 & $\mathbf{n} / \mathbf{a}$ & Portal hypertension \\
\hline $\mathbf{J N}$ & 44 & $\mathbf{M}$ & 40 & 30 & 14 & Portal hypertension \\
\hline ER & 57 & $\mathbf{M}$ & 20 & 38 & 9 & Gaucher's disease \\
\hline $\mathbf{J L}$ & $\mathbf{7 0}$ & $\mathbf{M}$ & $<10$ & 62 & 4 & Myelofibrosis \\
\hline \multicolumn{7}{|c|}{ Thrombocytopenia due to decreased production } \\
\hline $\mathbf{R O}$ & 57 & $\mathbf{F}$ & 12 & 87 & 6 & Phenylbutazone hypoplasia \\
\hline $\mathbf{Z C}$ & 66 & $\mathbf{M}$ & 40 & 129 & 7 & Idiopathic hypoplastic anaemia \\
\hline SH & 13 & $\mathbf{F}$ & 21 & 112 & 6 & Congenital hypoplastic anaomia \\
\hline AI & 36 & $\mathbf{M}$ & 54 & 109 & 7 & Diffuse histiocytic lymphoma \\
\hline ERP & 64 & $\mathbf{M}$ & 42 & 77 & 10 & Leukaemic reticuloendotheliosis \\
\hline
\end{tabular}

MPL $=$ mean platelet lifespan; $\mathbf{S} / \mathbf{H}=$ spleen $/$ heart ratio; $\mathbf{n} / \mathbf{a}=$ not available 


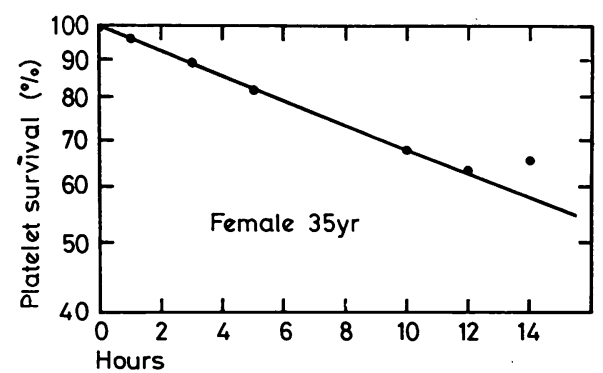

Fig. 1 Example of monophasic curve (patient $L S$ ).

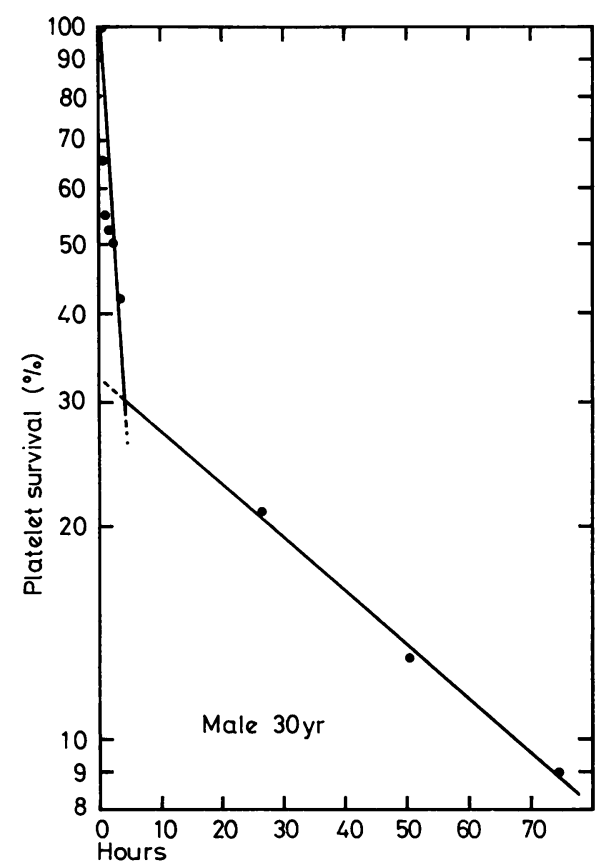

Fig. 2 Example of biphasic curve (patient EM).

those with biphasic curves although there was no correlation with the severity of the thrombocytopenia or with the degree of splenic sequestration. Of those with ITP, 13 subsequently underwent splenectomy, nine with good results (maintaining a normal platelet count) and four with a fair response (maintaining an improved but subnormal count). None failed completely to respond.

\section{Discussion}

There is still controversy about the value of isotope studies in determining the potential benefit of splenectomy in thrombocytopenic patients. All of our patients who underwent splenectomy showed a

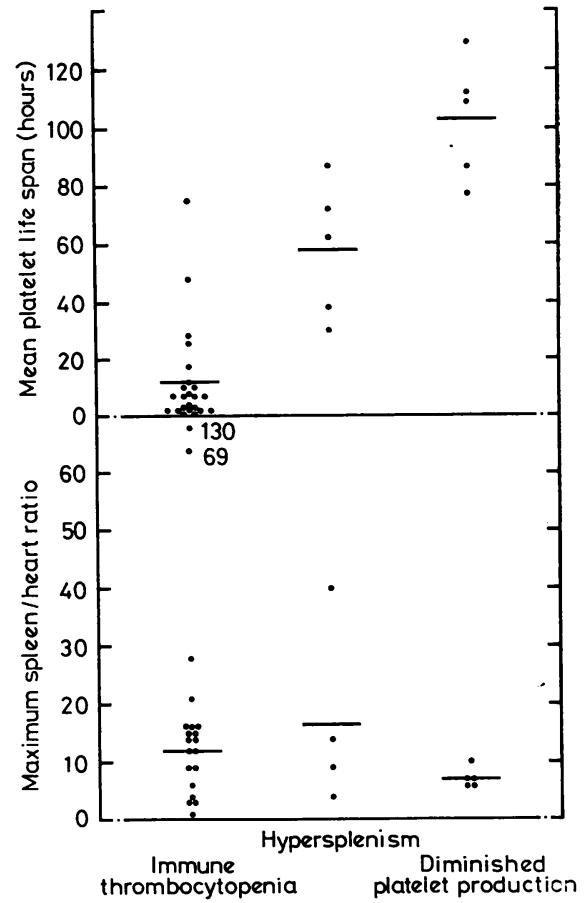

Fig. 3 Relationship of platelet lifespan and splenic sequestration (spleen/heart ratio) to diagnosis.

satisfactory partial or complete haematological response irrespective of the results of the isotope studies. Thus no one pattern of platelet survival or degree of splenic sequestration indicates a probable poor outcome, and these investigations are unlikely to be helpful for this purpose.

After the injection of labelled heterologous platelets, two factors influence splenic sequestration: (i) the degree of hypersplenism, dependent upon the splenic circulation through the pulp cords (as. opposed to the normal sinusoidal pathway), and endothelial adhesiveness of the sinus walls and pulp. cord spaces; and (ii) the changes of the platelet surface due to antibody coating.

The first factor alone results in a single exponential platelet disappearance curve, whereas the effects of both together produce the biphasic curve found in some patients with immune thrombocytopenia. This type of curve has not been seen in patients with other types of thrombocytopenia, except in one with hypoplastic anaemia who had received many platelet transfusions. The presence of both components will be apparent only if their time courses are substantially different; otherwise a single exponential or indeterminate curve will be seen. This depends on the relative importance of the hypersplenic and immune 
components, and it is not possible to decide in an individual patient which is producing the fast and which the slow phase of the survival curve. It would be of considerable interest to repeat the investigation after splenectomy in cases where the presplenectomy survival curve was biphasic but was not thought to be ethically justifiable. The immune component is the major factor in the failure of splenectomy due to increased destruction in the liver, and this is dependent on the amount of antibody activity carried by the platelets, that is, the product of antibody protein quantity and antibody avidity. Although measurement of the former is now an established technique (Dixon et al., 1975), the latter is not, and without it one cannot expect a close correlation between other investigations and the clinical outcome.

We thank Mrs Wendy Johnson for performing many of the isotope studies, Mr V. K. Asta for drawing the figures, and Dr J. M. Voke for helpful criticism of the manuscript.

\section{References}

Aas, K. A., and Gardner, F. H. (1958). Survival of blood platelets labeled with chromium. Journal of Clinical Investigation, 37, 1257-1268.

Adelson, E., Rheingold, J. J., and Crosby, W. H. (1957). Studies of platelet survival by tagging in-vivo with P-32. Journal of Laboratory and Clinical Medicine, 50, 570-576.

Aster, R. H., and Keene, W. R. (1969). Sites of platelet destruction in idiopathic thrombocytopenic purpura. British Journal of Haematology, 16, 61-73.

Barkhan, P. (1974). Blood and neoplastic diseasesother purpuras. British Medical Journal, 2, 376-378.

Branehög, I., Weinfeld, A., and Roos, B. (1973). The exchangeable splenic platelet pool studied with epinephrine infusion in idiopathic thrombocytopenic purpura and in patients with splenomegaly. British Journal of Haematology, 25, 239-248.

Cohen, P., Cooley, M. H., and Gardner, F. H. (1965).
The use of selenomethionine (Se-75) as a label for canine and human platelets (Abstract). Journal of Clinical Investigation, 44, 1036.

Dacie, J. V., and Lewis, S. M. (1975). Practical Haematology, 5th edition, p. 388. Churchill Livingstone, Edinburgh and London.

Dixon, R., Rosse, W., and Ebbert, L. (1975). Quantitative determination of antibody in idiopathic thrombocytopenic purpura. Correlation of serum and platelet-bound antibody with clinical response. New England Journal of Medicine, 292, 230-236.

Harker, L. A., and Finch, C. A. (1969). Thrombokinetics in man. Journal of Clinical Investigation, 48, 963-974.

Heyssel, R. M. (1961). Determination of human platelet survival utilizing C-14-labeled serotonin. Journal of Clinical Investigation, 40, 2134-2142.

Hirsch, E. O., and Gardner, F. H. (1952). The transfusion of human blood platelets. Journal of Laboratory and Clinical Medicine, 39, 556-569.

Leeksma, C. H. W., and Cohen, J. A. (1956). Determination of the life-span of human blood platelets using labelled diisopropylfluorophosphate. Journal of Clinical Investigation, 35, 964-969.

Murphy, S., and Gardner, F. H. (1971). Maintenance of platelet viability and functional integrity during storage. Vox Sanguinis, 20, 427-428.

Najean, Y., and Ardaillou, N. (1971). The sequestration site of platelets in idiopathic thrombocytopenic purpura: its correlation with the results of splenectomy. British Journal of Haematology, 21, 153-164.

Najean, Y., Ardaillou, N., Dresch, C., and Bernard, J. (1967). The platelet destruction site in thrombocytopenic purpuras. British Journal of Haematology, 13, 409-426.

Ries, C. A., and Price, D. C. (1974). [51-Cr] platelet kinetics in thrombocytopenia. Correlation between splenic sequestration of platelets and response to splenectomy. Annals of Internal Medicine, 80, 702-707.

Schwartz, A. D. (1974). A method for demonstrating shortened platelet survival utilizing recovery from aspirin effect. Journal of Pediatrics, 84, 350-354.

Requests for reprints to: Dr J. D. M. Richards, University College Hospital, Gower Street, London WC1R 6AU, UK. 